\title{
EQUILÍBRIO REFLEXIVO NA BIOÉTICA
}

\author{
Darlei Dall'Agnol \\ Universidade Federal de Santa Catarina/CNPq
}

\begin{abstract}
This paper aims at discussing the different applications of the method of justification known as 'reflective equilibrium" to bioethical problems. In the first part, it reconstructs its description made by John Rawls in "A Theory of Justice," his further distinction between "Narrow" and "Wide" Reflective Equilibrium and his own applications to eugenics and abortion. In the second part, it discusses the extension made by Norman Daniels of Rawls' theory of justice, his applications of the referred method and his contributions to bioethics, especially for the construction of a fair health care system. In the third part, it deals with the adoption of the method made by Beauchamp and Childress. In the conclusion, some criticism addressed to the method of the reflective equilibrium and its applications to bioethics are assessed.
\end{abstract}

KEYWORDS: justification, reflective equilibrium, justice, bioethics.

RESUMO: O presente artigo discute as diferentes aplicações do método de justificação conhecido como 'equilíbrio reflexivo' na bioética. Na primeira parte, reconstrói-se a caracterização do método feita por Rawls em "A Theory of Justice", a distinção posterior entre "Equilíbrio Reflexivo Estrito" e "Equilíbrio Reflexivo Amplo" e, finalmente, algumas aplicações do próprio Rawls na discussão da eugenia e aborto. Na segunda parte, discute-se as extensões feitas por Norman Daniels da teoria da justiça de Rawls, suas aplicações do método e suas próprias contribuições para a bioética, principalmente para a construção de um sistema de saúde justo. Na terceira parte, aborda-se a adoção do método pelos principialistas Beauchamp e Childress. Na parte conclusiva, algumas críticas feitas ao método são avaliadas a partir das aplicações feitas à questões de bioética.

PALAVRAS-CHAVE: justificação, equilíbrio reflexivo, justiça, bioética. 


\section{INTRODUÇÃO}

Em nenhum outro domínio da ética pode-se encontrar tanto dissenso quanto na bioética. Quase nem se precisaria mencionar as profundas discordâncias existentes nas discussões sobre questões relacionadas com o início e o fim da vida-aborto, eutanásia etc., pois os debates sobre, por exemplo, aplicações biotecnológicas na medicina reprodutiva que, para alguns, lembram práticas eugênicas, também estão longe de qualquer consenso. A utilização do método de justificação conhecido como 'equilíbrio reflexivo', supostamente capaz de produzir algum tipo de base que levaria a consensos, tem sido feita por diversos bioeticistas, mas também recebeu inúmeras críticas incluindo a de proporcionar uma justificação inconclusiva, ou seja, muito abrangente e indeterminada. Essa crítica será avaliada mais adiante. Mas, se não alcançamos consenso ainda sobre esses temas, que tipo de "contribuição metodológica significativa" se poderia esperar do equilíbrio reflexivo? O objetivo principal desse artigo é rediscutir as possíveis contribuições desse procedimento metodológico de justificação para a bioética, bem como analisar o seu alcance e limites e avaliar algumas críticas endereçadas a ele recentemente.

Para alcançar esses objetivos, o trabalho será dividido em três partes. $\mathrm{Na}$ primeira, será brevemente reconstruída a concepção de equilíbrio reflexivo em John Rawls bem como as suas principais reformulações e aplicações do método ao longo de sua obra. $\mathrm{Na}$ segunda parte, serão discutidas as aplicações e a extensão da sua teoria da justiça feitas por Normal Daniels para construir um sistema justo de saúde e, na terceira parte, as implicações da adoção do método feita por Beauchamp e Childress no livro clássico da bioética Principles of Biomedical Ethics. Nas considerações finais, as críticas feitas serão analisadas bem como será discutido o alcance e os limites do equilíbrio reflexivo na bioética.

\section{Equilíbrio Reflexivo em Rawls}

\section{1 - 0 problema da justificação em $A$ Theory of Justice}

Embora o filósofo americano John Rawls atribua a discussão do processo de ajuste mútuo entre princípios e julgamentos ponderados às observações feitas por Nelson Goodman sobre a justificação das inferências 
indutivas e dedutivas, a sua utilização em larga escala na bioética e em outros domínios da ética, da filosofia política e da própria bioética foi feita exatamente a partir de seu agora clássico livro de filosofia moral $A$ Theory of Justice, publicado em 1971, um dos mais importantes do final do Século XX. Em Goodman, não há o uso da expressão 'equilíbrio reflexivo', mas aparece a ideia de que "princípios de inferência dedutiva são justificados pela sua conformidade com práticas dedutivas aceitas. A sua validade depende da sua concordância com inferências dedutivas particulares que nós realmente fazemos e aprovamos” (1983, p.63). Por conseguinte, a justificação não poderia ser feita a partir de axiomas auto-evidentes tomados como primeiros princípios para determinadas conclusões particulares como procede um fundacionalista (por exemplo, Descartes: da indubitabilidade do cogito para a inferência de várias outras verdades empíricas ou matemáticas etc.). No fundo, haveria apenas suporte mútuo entre princípios e inferências particulares, um ponto também ressaltado por Wittgenstein em Da Certeza: regras e proposições empíricas formam sistema de crenças (§105, 126, 140, $142,225,286,410)$. Goodman, todavia, desconfiava da circularidade do procedimento, embora o considerasse um "círculo virtuoso". Mais do que isso, Goodman antecipa a necessidade de correção mútua entre princípios e julgamentos: "Uma regra é reformada se ela conduz a uma inferência que nós não estamos querendo aceitar; uma inferência é rejeitada se ela viola uma regra que nós não estamos querendo mudar." (1983, p.64, itálicos no original). Esse é o procedimento que será adotado e desenvolvido por Rawls.

Em $A$ Theory of Justice, ele sustenta que certos princípios de justiça seriam contratados na posição original (um experimento de pensamento por ele criado onde pessoas racionais, livres e iguais, sob o véu da ignorância, por exemplo, abstraindo as condições individuais de sua efetiva inserção social, pactuam normas éticas fundamentais) e que uma descrição das características desse constructo corresponderia aos julgamentos cotidianos ponderados, isto é, aqueles julgamentos onde as capacidades morais são bem exercidas, embora não totalmente isentas de erro, ou seja, as intuições morais. Por exemplo, certas intuições consideram a escravidão moralmente condenável, a discriminação racial injustificável, mostram que ninguém deveria tirar vantagem individual de uma eventual função que ocupa publicamente etc. Por isso, na posição original, as pessoas escolhem princípios de justiça sob condições de imparcialidade e, então, haveria equilíbrio entre julgamentos cotidianos e princípios ético-filosóficos. Essa estabilidade é chamada por 
Rawls de "equilíbrio reflexivo" (daqui para frente, ER) e é descrita da seguinte maneira: "É um equilíbrio porque ao menos nossos princípios e julgamentos coincidem; e é reflexivo, pois nós sabemos a quais princípios nossos julgamentos se conformam e de quais premissas eles são devidos.” (RAWLS [1971: 20]; 1999, p.18). O equilíbrio é um ideal de coerência; a reflexividade é uma propriedade cognitiva, um atributo da racionalidade das partes contratantes. Embora reconhecendo que tal equilíbrio não é estável definitivamente (esse ponto será retomado mais adiante), pois está permanentemente aberto a revisões dos julgamentos, Rawls pensa que encontrou uma descrição da posição original que se encaixa nas convicções cotidianas, por exemplo, na crença comum de que todas as pessoas são livres e iguais.

Uma crítica recorrente a esse procedimento de justificação é a de que ele é, de fato, circular. Como Goodman notou, há circularidade na justificação de princípios a partir de julgamentos que são aceitos cotidianamente. Se Rawls quer usar a posição original como procedimento de escolha de princípios e justifica a sua adoção a partir do que se considera efetivamente aceito, então é necessário dar razão a Tugendhat (1984) e dizer que há uma petição de princípio rondando o equilíbrio reflexivo. Em que medida essa crítica é fatal para os propósitos da teoria da justiça de Rawls não será avaliado aqui, embora eu pense que esse é um problema grave para toda a ética contratualista (cf. DALL'AGNOL, 2004, p.127).

O RE exige, segundo Rawls, a revisão contínua tanto dos princípios quanto dos julgamentos ponderados e o seu objetivo central seria ajustar ambos num processo "de cima para baixo", de "frente para trás," aparando "uma aresta aqui outra ali" etc., de algum modo indefinido, buscando coerência no todo, ou seja, eliminando crenças conflitantes no sistema moral. Não se pode, todavia, assumir que o equilíbrio seja definitivamente estável: é necessário questionar um julgamento ponderado a partir de um princípio, reformular os próprios princípios aprimorando-os, sofisticar a teorização harmonizando-a com a empiria etc., construindo uma ética coerente e integrada com a visão do mundo como um todo.

Para Rawls, o procedimento metodológico adotado, entretanto, é problemático em vários sentidos: primeiro, está aberto a "várias interpretações;" segundo, talvez não seja "único;" terceiro, mesmo que seja único, talvez não seja atingível (é um procedimento ideal apenas); finalmente, pode variar de pessoa para pessoa mesmo num grupo homogêneo (cf. 
RAWLS [1971: 48-51]; 1999, 42s). Em outros termos, Rawls estava aparentemente ciente do alcance e dos limites de seu próprio método de justificação. Não haveria, entretanto, alternativa melhor, pois não há, para Rawls, nem nas ciências nem na ética, princípios absolutamente autoevidentes que poderiam servir de fundamentos definitivos para o saber e para as ações humanas.

Para entender melhor esse procedimento, convém citar os princípios da teoria da justiça como fairness defendidos por Rawls. São eles: primeiro, o da igualdade no estabelecimento de direitos e deveres e, segundo, o que sustenta que certas desigualdades, por exemplo, em riqueza e autoridade, serão permitidas se favorecem a todos, especialmente os menos privilegiados da sociedade ([1971: 14-15]; 1999, p.13). Essa é a formulação inicial desses princípios, reformulados continuamente ao longo da obra e entre a edição original e a revisada (por exemplo, em RAWLS [1971: 60] aparece somente "liberty" enquanto que em RAWLS, 1999, p. 53, aparece a expressão "basic liberties”). As outras formulações provisórias não nos interessam aqui exceto para observar que o segundo princípio também chamado 'princípio da diferença' será reformulado a partir da noção de igualdade de oportunidades, ou seja, as desigualdades serão justas se estiverem relacionadas com posições e funções abertas a todos.

A formatação final dessas normas fundamentais da justiça como fairness, ao menos em $A$ Theory of Justice, é feita mais adiante (\$46) somente depois de estabelecer regras de prioridade entre os princípios, mas esse ponto será discutido somente mais adiante. Em outros termos, tanto o primeiro quanto o segundo princípio estariam em equilíbrio reflexivo com os julgamentos que condenam, como foi visto, a discriminação racial e religiosa, ou seja, há basicamente coerência entre eles. Não se teria esse equilíbrio sobre outras questões de justiça, por exemplo, sobre se um novo imposto no Brasil (digamos, sobre o cheque) com função redistributiva ou para combater a miséria ou para melhorar a saúde é justo ou não. A obra de Rawls pretende jogar uma luz sobre esse ponto e essa é a principal contribuição que ele espera fazer através de seu aparato conceitual procedimentalista (posição original, véu da ignorância etc.) para alargar a compreensão do que é justo ou injusto incluindo a justificação de certas desigualdades sociais e econômicas. Todavia, já cabe perguntar se não são somente os julgamentos do próprio Rawls que afirmam a família monogâmica, a propriedade privada dos bens de produção, o livre mercado etc. (cf. [1971: 7]; 1999, p. 6) que poderiam 
estar em equilíbrio com os seus princípios acima citados (ou justificariam a adoção daqueles princípios) o que mostra um aspecto conservador de seu pensamento ao apoiar-se em intuições cotidianas da sociedade democrática liberal e capitalista da maioria dos países ocidentais. Somente mais tarde, Rawls reconhecerá que uma teoria da justiça como fairness não é universal, mas aplicável somente a certas sociedades. Além disso, ele insiste nas liberdades básicas do liberalismo tradicional, a saber, as políticas (de votar e ser votado), de reunião ou assembleia, de expressão ou fala, de consciência e de pensamento, de ter propriedade privada, de não ser preso ou sequestrado arbitrariamente (cf. [1971: 61]; na edição revista de $A$ Theory of Justice, Rawls acrescenta a liberdade contra opressão psicológica, contra agressão física e contra desmembramento, isto é, a integridade da pessoa (cf. 1999, p. 53) evidenciando uma pequena revisão de conteúdo e não apenas estilística ou gramatical).

$\mathrm{Na}$ primeira formulação provisória dos princípios fundamentais menciona-se apenas, no caso do primeiro princípio, de igualdade de direitos e obrigações, sem especificar quais seriam esses direitos. Uma pergunta relevante é por que Rawls especifica nas reformulações do primeiro princípio os direitos apenas em termos de liberdades? Os julgamentos ponderados cotidianos não poderiam exigir algo diferente ou outros direitos fundamentais, por exemplo, à vida também foram defendidos por liberais clássicos como Locke? Nesse sentido, uma crítica como a de Dworkin, a saber, que opera um direito ao igual respeito como sendo mais básico na posição original parece fazer sentido (cf., DWORKIN, 1975, p. 46). Pode-se perguntar, no contexto temático do presente artigo, então: por que não figura no primeiro princípio um direito igual aos cuidados básicos de saúde? Essa questão será discutida mais adiante.

Sempre é possível perguntar, também, se tais princípios não seriam compatíveis com outras instituições sociais e com outras formas de organização estatal e econômica que influenciariam a formação de outros julgamentos ponderados. Nesse sentido, o procedimento justificatório de Rawls não apenas seria circular, mas parece reafirmar certos preconceitos profundamente enraizados nas instituições atualmente existentes de determinadas sociedades. Para dar outro exemplo da parcialidade do procedimento justificatório: um nazista poderia alcançar equilíbrio entre seus princípios "trasímaconianos" de justiça (justo é o convém ao mais forte) e seus julgamentos cotidianos sobre eugenia ou sobre a superioridade da raça 
ariana. Para analisar criticamente essa e outras dificuldades do método de justificação ER será reconstruída a seguir, mais detalhadamente, a discussão de uma questão importante para a bioética, a saber, o problema do valor da saúde e o consequente direito básico aos cuidados de saúde.

Não é difícil ver como Rawls pensa que a partir de seus princípios de justiça sigam-se não apenas as instituições básicas da sociedade, a saber, uma Constituição, um governo com poder judiciário etc. e as outras acima citadas mas, também, um índice de bens primários que todas as pessoas racionais devem querer (por ser racional querer os meios mais efetivos para certos fins desejados) independentemente de quais sejam seus projetos de vida. Tais bens primários seriam os seguintes: direitos e liberdades, oportunidades e poderes, renda e riqueza e auto-respeito (RAWLS [1971: 92]; 1999, p. 79). Mas por que entre esses bens não figura algo tão fundamental quanto a saúde que impede ou dificulta qualquer projeto de vida boa e que é racional buscá-la? Como será visto mais adiante, alguns bioeticistas criticam Rawls por deixar certos bens primários que aparentemente todos consideram fundamentais cotidianamente, por exemplo, a saúde, fora de sua lista de bens primários.

\section{2 - Equilíbrio Reflexivo Amplo em Political Liberalism}

Embora em $A$ Theory of Justice Rawls reconheça implicitamente que há tipos de equilíbrio reflexivo, por exemplo, ou entre alguns princípios e julgamentos - o até agora considerado ER ou entre todas as crenças, incluindo princípios e juízos ponderados cotidianamente, mas também crenças empíricas, todas as teorias etc., somente mais tarde ele utilizará a distinção entre Equilíbrio Reflexivo Estreito (narrow, daqui pra frente ERE) e Equilíbrio Reflexivo Amplo (wide, ERA). Na sua obra Political Liberalism, de 1993, a diferença entre os dois aparece claramente introduzindo elementos até certo ponto negligenciados na primeira grande obra. Por exemplo, não há níveis privilegiados de princípios em relação a julgamentos particulares e, portanto, todos os graus de generalidade devem ser considerados igualmente (1993, p.8); o estabelecimento de uma concepção razoável de justiça depende de uma confrontação entre a minha e a tua concepção (1993, p.28) dando uma perspectiva mais intersubjetiva à justificação, questão essa que Rawls nem queria cogitar em $A$ Theory ([1971: 50]; 1999, p. 44)etc.. Não é o objetivo aqui, entretanto, avaliar as relações entre as duas obras máximas de Rawls, pois isso nos desviaria demais dos objetivos do presente trabalho. 
O equilíbrio reflexivo, reconhece Rawls em Political Liberalism (p.95-6), pode ser alcançado por diferentes teorias e, mesmo assim, ser interpretado diferentemente. Essa foi uma dificuldade do ERA detectada desde o início. Ele ilustra esse ponto contrapondo seu construtivismo ou contratualismo com o intuicionismo racional. Os intuicionistas podem aceitar o argumento da posição original e usar o equilíbrio reflexivo para chegar a uma descrição de certos valores considerados fundamentais. Todavia, diferentemente de Rawls, sustentam que julgamentos morais, se forem corretos, descrevem um reino independente de fatos morais e, se devem ser revisados e corrigidos, é porque não o fizeram adequadamente, enquanto que um construtivista rawlsiano sustenta que o problema pode estar na maneira como o procedimento molda os princípios da razão prática em conjunção com concepções de sociedade e de pessoa e, sendo a razão falível, tal revisão deve ser contínua e indefinida. Como pode ser visto, não há diferença substancial nesse ponto considerando a obra anterior, ou seja, em relação ao ERA não há mudança significativa.

Há, entretanto, algo novo na segunda grande obra de Rawls que deve ser brevemente discutido. Todas as mudanças, segundo o autor de Political Liberalism, podem ser entendidas como uma correção do enfoque dado à questão da estabilidade na parte III de $A$ Theory of Justice, pois ela seria inconsistente com a concepção como um todo (RAWLS, 1993, p. xv-xvi). Em outros termos, o reconhecimento do "fato do pluralismo razoável" (1993, p. xvii) e da consequente necessidade de um consenso sobreposto (overlapping consensus) entre as diversas concepções religiosas, filosóficas, morais etc. abrangentes (comprehensive doctrines) vigentes em sociedades cosmopolitas atuais como a norte-americana ou a brasileira coloca novos problemas para a questão da estabilidade entre julgamentos cotidianos e princípios. Desse modo, coloca também um problema para a estabilidade da concepção de justiça como fairness para não falar da estabilidade da estrutura básica da sociedade como um todo. Por conseguinte, o ERA deverá ser alcançado agora politicamente, isto é, numa conversação real entre essas concepções razoáveis (que possuem senso de justiça e uma concepção de bem que não pode ser recusada) e não pelo puro procedimento racional pressuposto em $A$ Theory. A distinção entre racional e razoável torna-se importante a partir do Political Liberalism (cf. RAWLS, 1993, p. 43s e SILVEIRA, 2008, p. 96s.). Essa distinção foi também feita por Wittgenstein em Da Certeza questionando aquilo que pode estar "beyond all reasonable doubt" (§607) e um estudo comparativo entre esses filósofos seria interessante, mas não pode ser feito 
aqui. Não se trata mais, no Political Liberalism, meramente de um ERE simples entre princípios e julgamentos para um único individuo (até mesmo para um nazista pensando sobre eugenia), mas de um Equilíbrio Reflexivo Amplo incluindo justificações públicas para uma sociedade bem ordenada, isto é, que possua uma concepção pública de justiça.

Em diversas passagens da obra Political Liberalism, entretanto, Rawls reconhece que sua teoria da justiça como fairness precisa ser estendida para cobrir a questão de nossos deveres para com as futuras gerações, com a aplicação a questões internacionais e ao estabelecimento de princípios de um sistema de saúde e da nossa relação com animais e a natureza (1993, p. 244s). Ele não se preocupou suficientemente com essas questões na primeira obra. Talvez, aqui, esteja sendo dada uma resposta a objeções tal como a que foi feita por Norman Daniels: "não há teoria da justiça distributiva para o sistema de saúde porque ninguém está doente” na posição original (DANIELS, 1995, p. 43). Voltarei a essa crítica a seguir.

Esses reconhecimentos da necessidade de um consenso sobreposto devido ao fato do pluralismo razoável e de extensões da teorização da justiça sobrecarregam, de algum modo, o procedimento justificatório do ERA: ele deverá produzir algum tipo de convergência intersubjetiva e não apenas uma coerência "interna”, num único indivíduo, entre julgamentos e princípios. Para que isso possa ser alcançado, o ERA deverá levar em consideração não apenas os princípios de justiça supostamente contratados na posição original, mas também todas as concepções morais alternativas, todas as teorias sobre a pessoalidade, todas as teorias rivais da justiça, todas as teorias sobre o desenvolvimento moral, todas as teorias empíricas sobre a natureza da sociedade e as relações sociais etc.. Essa é, certamente, uma tarefa hercúlea. Quer dizer, deve-se procurar produzir uma harmonização entre todas as crenças, ou como Rawls já tinha declarado em $A$ Theory “... justification is a matter of mutual support of many considerations, of everything fitting togehter into one coherent view.” ([1971: 21; 579]; p. 19; 507; itálicos acrescentados). Se fosse alcançável, esse tipo de equilíbrio mereceria o nome de "Equilíbrio Reflexivo Monista", mas se o próprio Rawls considerou em $A$ Theory o ERE um "ideal filosófico", seria o ERA menos utópico?

\section{3 - Outras aplicações do ERA feitas por Rawls}

O procedimento justificatório adotado por Rawls tem, todavia, méritos que mostram que uma desqualificação apressada é, de fato, injusta. $\mathrm{O}$ 
ERA não é apenas um expediente de justificação, mas de correção e ajuste das crenças. Para ilustrar, é possível perguntar pelas manifestações do próprio Rawls sobre problemas bioéticos que, embora sejam escassas, existem. Por exemplo, ele discute em $A$ Theory o tema da eugenia manifestando-se claramente a favor da eugenia positiva (RAWLS, [1971: 108]; 1999, p. 92). Outras questões bioéticas também podem ser examinadas a partir dos procedimentos metodológicos rawlsianos como, por exemplo, a questão do aborto (cf. o próprio RAWLS, 2001, p. 117). Ao discutir se a questão do aborto é um tema constitucional essencial, Rawls sustenta que isso não é claro e que ela pode levar a grandes conflitos, mas alguns valores devem ser resguardados: a lei pública deve mostrar um respeito apropriado pela vida humana; deve regular as instituições através das quais a sociedade se reproduz; deve assegurar a igualdade das mulheres; deve impedir que uma doutrina abrangente possa decidir o caso (RAWLS, 2001, p. 117). De fato, Rawls parece não ter uma posição clara sobre o assunto, pois não é dito se o aborto deveria ser proibido, na medida em que representa um desrespeito à vida humana ou se deveria ser permitido, como de fato é nos EUA desde o famoso caso Roe v. Wade, de 1971, justificado, entre outras coisas, pela autonomia da gestante de decidir livremente numa sociedade onde vigora o "fato do pluralismo razoável".

O aparato teórico rawlsiano permite outras aplicações, embora indiretamente, às questões bioéticas, ou seja, "poderíamos nos imaginar na posição original, sob o véu da ignorância, e nos perguntar que regras poderíamos contratar, sob tais circunstâncias, que viriam a normatizar o aborto, a eutanásia, as pesquisas biotecnológicas etc." (cf. DALL'AGNOL, 1994, p. 126). Por exemplo, alguém poderia se imaginar sob o véu da ignorância e, não sabendo se será um feto saudável ou uma gestante, se aprovaria leis que permitem o aborto por qualquer razão no primeiro trimestre de gestação. Também poderia se perguntar nessa situação hipotética, não sabendo se será um profissional da saúde ou uma pessoa comatosa há 10 anos sem perspectiva realista de cura, se aprovaria o desligamento dos artefatos tecnológicos que dão suporte à vida estabelecendo também quem deveria fazer isso. Seria favorável a que tipo de eutanásia? Somente passiva? Voluntária ou também não-voluntária? Finalmente, sob o véu de ignorância, sem saber a que geração pertence, aprovaria políticas de melhoramento genético, de eugenia positiva? 
Outro bom exemplo do uso do ERA para aperfeiçoar os princípios ou os julgamentos cotidianos talvez tenha sido fornecido pelo próprio Rawls ao longo de suas reformulações da teoria da justiça como fairness. Sem querer entrar nas particularidades das mudanças, é perceptível também a diferença de tonalidade em relação a esse ponto feita em Justice as Fairness: a Restatement, primeiramente publicada em 2001. Nela, claramente lê-se que todos os cidadãos são beneficiários de certos serviços do governo que deve providenciar vários bens básicos e serviços tais como os cuidados com a saúde assegurando também água e ar limpos etc. e que "todos esses itens podem (se necessário) ser incluídos no índice de bens primários.” (RAWLS, 2003, p. 172) A referência constante aqui, feita pelo próprio Rawls, é exatamente ao livro de Daniels, Just Health Care que será abordado a seguir. Todavia, Rawls parece não ter compreendido, como será visto, a proposta de Daniels exatamente.

Outro ponto precisa ser notado aqui: ao responder a uma crítica à sua teoria da justiça como fairness feita por A. Sen, a saber, que a lista dos bens primários é inflexível demais, Rawls elenca alguns arranjos que uma sociedade de cidadãos-proprietários (sua proposta em termos econômicos que nem é capitalista nem socialista liberal) deveria providenciar, entre eles está "um nível básico de cuidados de saúde para todos” (RAWLS, 2003, p.168176). Em outros termos, se a saúde é uma condição para o exercício de direitos e deveres básicos, então ela deve ser desejada por todas as pessoas racionais e figurar na lista dos bens primários. É claro que isso traz problemas para fazer uma comparação interpessoal desses bens, mas este problema não será aprofundado. Até que ponto isso compromete a prioridade do justo sobre o bom ou revela a efetiva congruência entre eles, num sentido matemático, não será também discutido aqui. Aparentemente, não há razões convincentes para priorizar um em relação ao outro.

A reformulação da teoria da justiça como fairness desde $A$ Theory (1971), passando pelo Political Liberalism (1993) até o Restatement (2001) parece ser uma boa ilustração das mudanças capazes que deveriam ser produzidas, seja nos princípios, seja nos julgamentos particulares, pelo equilíbrio reflexivo. Para ilustrar um pouco melhor esse ponto, considere as diferenças nas formulações do primeiro princípio. Em $A$ Theory, sua formulação final é esta: "each person is to have an equal right to the most extensive total system of equal basic liberties compatible with a similar system of liberty for all” ([1971: 302]; 1999, p. 220). Já no Political 
Liberalism, a formulação é a seguinte: "each person has an equal claim to a fully adequate scheme of equal basic rights and liberties, which scheme is compatible with the same scheme for all; and in this scheme the equal political liberties, and only those liberties, are to be guaranteed their fair value”. (1993, p. 5) Não é possível analisar aqui de forma pormenorizada as todas as mudanças, pois não é esse o objetivo deste trabalho.

Algumas diferenças, entretanto, na formulação são realmente significativas: não tanto a mera substituição da palavra "liberty" por "basic liberties," já apontada anteriormente, mas uma distinção entre tipos de liberdades e a reserva de um lugar especial para as liberdades políticas. Seria esse o resultado mais significativo da aplicação do ERA feita pelo próprio Rawls ao longo de 20 anos? O que poderia ser incluído no "equal basic rights” que não fossem liberdades? Lembrando a discussão acima, o direito, talvez o mais básico de todos, à vida? Um direito fundamental aos cuidados de saúde? Antes de procurar uma resposta para essas questões, é necessário considerar outras aplicações desse procedimento justificatório feitas por outros eticistas inspirados em Rawls para poder voltar a ele e avaliá-lo criticamente.

\section{As aplicações e extensões de Daniels do ERA}

Em vários trabalhos importantes, Norman Daniels procurou estender a teoria da justiça de Rawls para contribuir na construção de um sistema justo de saúde. Para compreender bem esse empreendimento, é necessário fazer duas observações. Primeira, Daniels reconhece que a sua primeira tentativa de aplicar a teoria rawlsiana da justiça como fairness à construção de um sistema justo de saúde teve várias dificuldades (1996, p. 345) e, de algum modo, falhou (1985, p. 10) por não ter clareza sobre que tipo de bem social é o cuidado com a saúde: uma mera commodity ou algo especial? Se fosse do primeiro tipo, poderia variar em distribuição desigual entre os indivíduos como as outras diferenças sociais e econômicas legitimadas pelo princípio da diferença? Mas, sendo do segundo tipo, como dar conta da especificidade em relação aos outros bens sociais? A segunda observação é que Daniels, posteriormente e para responder à última pergunta, elaborou um enfoque próprio da justiça distributiva cujas principais ideias são apresentadas nos três primeiros capítulos de Just Health Care (sendo o central republicado como capítulo 9 de seu livro Justice and Justification: reflective equilibrium in theory and practice). 
Mesmo correndo o risco de uma simplificação, tal enfoque pode ser denominado de 'igualdade de oportunidades fair (equitativa)' e a tese central é que não existe um direito simpliciter à saúde, mas um direito aos cuidados básicos de saúde que depende de uma teoria geral da justiça para ser justificado e de uma série de instituições de saúde (hospitais, clínicas, postos de saúde, programas públicos preventivos, empresas seguradoras ou de planos de saúde, centros de treinamento para profissionais da saúde, agências governamentais etc.) Daniels, então, pergunta-se se tal direito é compatível com desigualdades na distribuição do bem-estar e se ele não fere as liberdades individuais. Apesar das tensões, entretanto, eles não são incompatíveis. $\mathrm{O}$ enfoque de Daniels está parcialmente baseado numa teoria das necessidades dos cuidados da saúde construída a partir do modelo biomédico de saúde e não em preferências. Ele contém os seguintes elementos: (1) nutrição adequada, abrigo; (2) condições de trabalho e de moradia saudáveis, seguras, não poluídas; (3) condições de exercício físico e descanso e outras características do estilo de vida: (4) serviços médicos pessoais de reabilitação, cura e prevenção e (5) diversos serviços não-médicos sociais e pessoais de suporte (1985, p. 32; 1996; p. 187). O apelo à categoria da necessidade, apesar de algumas dificuldades teóricas, explica o que há de especial nos cuidados de saúde enquanto bem social. Contra as objeções de que o discurso sobre necessidades é vago, que existiriam "necessidades" extravagantes para alguns indivíduos, que não é possível comparar necessidades etc., Daniels distingue necessidades-ao-longo-da-vida (por exemplo, comida, abrigo etc.) de necessidades-acidentais (adventitious), contingentes, relativas a certos momentos ou projetos de vida (1985, p. 26). As primeiras devem ser satisfeitas para que as pessoas possam funcionar como membros naturais/normais da espécie humana enquanto animais sociais. As necessidades dos cuidados de saúde são do primeiro tipo. A não satisfação dessas necessidades impede a "igualdade de oportunidades" na realização dos "planos de vida” das pessoas, noções fundamentais dos princípios de justiça de Rawls mencionados acima. Por isso, a saúde é um bem social muito especial.

O ponto que interessa, aqui, é exatamente essa extensão da teoria da justiça rawlsiana aplicando-a a questões bioéticas. Já foi mencionado que Daniels critica a lista de bens primários de Rawls por não considerar na sua teoria da justiça distributiva questões relacionadas com o sistema de saúde, pois supostamente nenhuma pessoa, entendida apenas como ser livre e igual, 
estaria doente. Tal lista é, para Daniels, muito simplificada (1985, p. 43) sendo necessário então acrescentar os cuidados de saúde nela. Todavia, esse acréscimo levaria a uma dificuldade, a saber, a de ter que considerar comparativamente esses bens primários dando prioridade para uns e não para outros. Este problema é apontado por Rawls como uma dificuldade tão grande para o utilitarismo que o torna uma teoria ética inaplicável. Por isso, uma estratégia mais promissora, de acordo com Daniels (1985, p. 45), é acrescentar nas instituições da estrutura básica da sociedade aquelas instituições relacionadas com os cuidados de saúde para proporcionar a realização da igualdade de oportunidades justa. Portanto, a extensão de Daniels da teoria de Rawls é, em linhas gerais, esta: visto que a satisfação das necessidades de saúde tem um efeito importante na distribuição das oportunidades, as instituições de saúde (mencionadas acima) devem ser reguladas pelo princípio da igualdade de oportunidades e não apenas para cargos e empregos, mas também para questões de planos de saúde ou segurosaúde. Daniels divide tais instituições em quatro níveis para melhor realizar o ideal rawlsiano da igualdade de oportunidades, das preventivas, passando pelas curativas e de assistência social até as paliativas, mas esse ponto não será desenvolvido aqui. Ele teve que "modificar a teoria de um modo modesto e razoável.” (DANIELS, 1996, p.345) Modéstia à parte, há mudanças importantes e soluções aparentemente melhores que as do próprio Rawls para certos problemas, por exemplo, não remendar a lista de bens primários, mas acrescentar instituições de cuidados da saúde na estrutura básica da sociedade.

É necessário esclarecer outro ponto aqui mostrando, de fato, a continuidade em espírito do trabalho rawlsiano. Assim como há, na teoria da justiça como fairness de Rawls, prioridade do princípio das iguais liberdades básicas sobre o princípio da diferença, também há prioridade entre o "subprincípio" da igualdade de oportunidades em relação ao "subprincípio" das vantagens para os menos favorecidos. Em outros termos, é necessário garantir antes a realização das liberdades, depois das oportunidades e finalmente das vantagens especiais para os menos privilegiados. Daniels segue essa ordem lexical na sua concepção rawlsiana de justiça distributiva: ele simplesmente rejeita a ideia de que os que mais precisam de cuidados possam recebê-los antes, se isso não satisfizer a condição de contribuir para a igualdade de oportunidades (cf. 1996, p. 346). Para ilustrar esse ponto: transplantes de órgãos podem ser feitos a partir de uma política que leva em 
consideração ou (i) o número de anos do paciente maximizando o benefício do procedimento ou (ii) uma lista de espera ou (iii) o grau de necessidade do paciente medida, por exemplo, pelo MELD ou (iv) outro critério qualquer. Daniels rejeitaria a última alternativa (a maior necessidade) e, querendo recolocar as pessoas no mercado das iguais oportunidades de cargos e funções, optaria pela primeira alternativa. Todavia, essa ideia é, em alguma medida, contra-intuitiva (ou, ao menos, deveria ser melhor justificada), pois um indivíduo deve ter suas necessidades de cuidados básicos de saúde satisfeitas mesmo se isso não o recoloca no mercado. Dizer que uma pessoa tem o direito a cuidados de saúde ou que é bom para ela ter seu bem-estar incrementado significa dizer algo a mais do que simplesmente apontar para realização da igualdade de oportunidades em cargos e postos de trabalho. Além disso, mesmo se o procedimento do véu da ignorância fosse adotado para escolher princípios de justiça para alocar recursos para a saúde, não é claro que se deixaria por último a satisfação das necessidades dos que mais precisam de cuidados de saúde. Essa é uma razão, talvez não conclusiva, para se questionar a própria teoria rawlsiana de Daniels.

Pode-se, agora, perguntar até que ponto tal extensão, ou melhor, essa reformulação da teoria da justiça, foi obtida pela utilização do procedimento de ERA ou implicada por ele. Pela função que o ERA deveria desempenhar, essa seria a conclusão que naturalmente se poderia tirar. Mas uma resposta mais satisfatória para essa questão e uma eventual discussão sobre as contribuições do ERA para a bioética podem ser encontradas no livro de Daniels Justice and justification: reflective equilibrium in theory and practice, de 1996. A tese central do livro é a de que o método ERA não apenas pode ser usado para a justificação de teorias éticas, mas também oferece um guia efetivo para questões de ética prática (DANIELS, 1996, p. 1). Diferentemente do ERE que busca harmonia apenas entre princípios e julgamentos, o ERA proporcionaria, como aliás já foi visto brevemente acima, a justificação dos próprios princípios e julgamentos a partir da consideração de todas as crenças e evidências, de todas as teorias etc. Como não há crenças privilegiadas, isto é, não sujeitas a reformulações, mesmo a teoria de Rawls poderia ser, e, de fato foi, retocada. Como a discussão teórica do ERA já está se tornando repetitiva, é possível agora concentrar-se na parte prática, no último capítulo do livro intitulado "Wide Reflective Equilibrium in Practice” (DANIELS, 1996, p.333-350.), especialmente dedicado à questão metodológica na bioética. 
Citando o diagrama apresentado por Beauchamp e Childress num livro que será comentado na próxima seção, Daniels reconstrói o estado da arte da discussão metodológica da bioética para propor uma divisão de trabalho capaz de contemplar todas as contribuições. Eis o diagrama:

\section{Teorias Éticas}

\section{Princípios}

\section{Regras}

\section{Julgamentos particulares e ações}

As divergências mais significativas entre as diferentes abordagens bioéticas seriam devidas, segundo Daniels, a uma espécie de dieta metodológica unilateral: casuístas tais como Jonsen e Toulmin concentram-se em trabalhar a partir de 1 para chegar, no máximo, a 2; principialistas clássicos tais como Beauchamp e Childress e neoprincialistas como DeGrazia e Richardson concentram-se em 2 e 3; Gert, Culver e Clouser concentram-se em 4 etc. Enquanto uns procederiam indutivamente ("de baixo para cima”), outros trabalhariam dedutivamente ("de cima para baixo"). Estaria, então, declarada a guerra para a qual Daniels tem uma proposta de paz, de tolerância mútua entre as diferentes metodologias bioéticas, a partir do ERA, ou seja, a justificação na ética, particularmente na bioética enquanto ética aplicada, dependeria de um enfoque coerentista envolvendo todas as crenças em diferentes níveis. Citando Daniels sobre o conjunto de crenças envolvidas no ERA (ou, talvez, num "Equilíbrio Reflexivo Holista"):

Eu incluo aqui nossas crenças sobre casos particulares; sobre regras e princípios e virtudes e como aplicar ou agir a partir delas; sobre as propriedades que tornam corretas as ações, políticas e instituições; sobre o conflito entre enfoques consequencialistas e deontológicos; sobre a parcialidade e a imparcialidade e o ponto de vista moral; sobre motivação, desenvolvimento moral e compromissos morais e os limites da ética; sobre a natureza das pessoas; sobre a função e o papel da ética nas nossas vidas; sobre as implicações da teoria dos jogos, da teoria da decisão e os enfoques da racionalidade 
para a moralidade; sobre os modos que devemos responder ao ceticismo moral e ao desacordo moral; e sobre a própria justificação moral. (DANIELS, 1996, p.338-9)

De fato, Daniels garante a igualdade de oportunidades para todos os eticistas: todos os métodos contribuem de alguma maneira; todos os problemas, teóricos ou práticos, são relevantes; todos os casos são significativos; todas as teorias são valiosas (...). Se faltar emprego nessa divisão generosa de trabalho, procure um tema bioético ou ético e simplesmente inclua na lista!

Mas será o ERA capaz de produzir coerência suficiente entre todas essas crenças? Talvez seja agora o melhor momento para mencionar novamente a crítica a essa pretensão omni-abarcadora do ERA. John Arras (2007, p. 55) sustenta que a atratividade do ERA deve-se a seu ar inconclusivo e isto se explica por ser muito abrangente (englobar todas as crenças de todos os tipos) e indeterminado (não há uma indicação clara de como chegar a coerência completa de crenças contrárias). Seria o preço do ecletismo de ERA exigir tudo sem conseguir nada ou sem saber se e quando conseguiu algo? Antes de procurar responder a essa questão, é preciso analisar mais detalhadamente a adoção do ERA feita por outros bioeticistas, pelos assim chamados "principialistas" Beauchamp e Childress, para ver se esse é o caso.

\section{Equilíbrio reflexivo no principialismo}

Se o objetivo central do ERA é o de produzir um equilíbrio entre todas as crenças (sejam morais, empíricas, teóricas etc.) fazendo um ajuste constante buscando fundamentalmente coerência entre elas, então talvez a melhor ilustração dessa busca do melhor enfoque seja a revisão contínua, em seis edições diferentes, do "livro sagrado" da bioética, o Principles of Biomedical Ethics de Beauchamp e Childress. A influência é tão grande que os quatro princípios (autonomia, não-maleficência, beneficência e justiça) são a base da legislação brasileira sobre pesquisas envolvendo seres humanos, na famosa Res.196/96 do Ministério da Saúde. Embora pareça um mero exercício exegético, é importante reconstruir, aqui, antes de discutir os termos da adoção do ER pelos principialistas, as mudanças mais importantes de cada uma dessas edições procurando mostrar como o ER pode estar operando nas constantes revisões, especialmente a partir das três últimas edições. O objetivo, para além da mera exegese, é discutir criticamente as possíveis contribuições do ERA. 
Na primeira edição do Principles of Biomedical Ethics, publicada em 1979, Beauchamp e Childress apresentam os seguintes pontos de partida relevantes para a presente discussão: i) eles usam apenas duas das principais teorias éticas tradicionais, a saber, o utilitarismo e a deontologia, com especial menção a Mill e a Kant, mas também incorporando os trabalhos de Ross e Frankena para chegar aos princípios fundamentais (p.21-55); ii) eles elaboram o diagrama reconstruído acima na discussão de Daniels com a intenção de explicar, justificar e ilustrar a aplicação de princípios intermediários (midle level), mas, estranhamente, apesar de trabalharem "de cima para baixo," ou seja, dedutivamente de princípios para casos, indicam as flechas com direção contrária (cf. acima o diagrama); iii) a autonomia, a beneficência, a não-maleficência e a justiça (capítulos 3 a $\quad 6$ ) são explicitamente chamados "princípios"; iv) há um capítulo sobre "Ideals, Virtues and Integrity” (cap. 8), mas não há uma discussão com a ética de virtudes, v) há vários apêndices com 29 estudos de casos e os princípios códigos bioéticos (o Juramento Hipocrático, os Princípios da Ética Médica da AMA, o Código de Nuremberg, a Declaração de Helsinki, o Código para Enfermeiras). É preciso destacar, para posteriormente discutir o ERA, a presença de poucas teorias éticas, do uso de um procedimento exclusivamente dedutivista e de uma preocupação de aplicação de princípios a regras e casos.

$\mathrm{Na}$ segunda edição do livro, publicada em 1983, os autores afirmam no prefácio que "esta edição mantém a estrutura e as linhas gerais do argumento da primeira” (p.vii), mas também é dito que cada página foi revisada e os casos e a bibliografia foram atualizados, supondo-se então a incorporação de mais casos com características morais novas e relevantes e não contempladas na edição anterior. De fato, não há mudanças significativas nos capítulos sobre os princípios, mas, no capítulo 8 , sobre "Ideals, Virtues and Conscientious Action" foi introduzida a ideia de uma correlação entre princípios fundamentais e virtudes primárias (por exemplo, o princípio da beneficência corresponderia à virtude da benevolência) mostrando certa preocupação com as críticas ao formalismo vazio dos princípios feitas, provavelmente, a partir da ética de virtudes. O que essas mudanças significam em termos do tema central deste artigo: uma concessão à complexidade dos casos ou até mesmo à casuística? A necessidade de dar conta de outras teorias éticas rivais, principalmente a ética das virtudes, um enfoque alternativo a uma ética de princípios (cf. HOBUSS, 2011)? Estaria já operando implicitamente o ERA aqui? 
Na terceira edição do Principles, publicada em 1989, Beauchamp e Childress argumentam que "as forças da mudança que nos convenceram a reestruturar a primeira edição continuaram e esta terceira edição envolve mudanças ainda mais significativas que as que foram feitas na segunda. Todavia, o livro retém a mesma estrutura de capítulos e as linhas gerais do argumento.” (p. 7) As principais mudanças foram as seguintes: i) a introdução de muitos assuntos novos em cada capítulo tais como os vários tópicos sobre AIDS, nutrição artificial e hidratação e, consequentemente, uma adequação de cada capítulo dedicado aos princípios a esses temas, por exemplo, discutindo a justiça não apenas com perspectivas libertarianistas e igualitaristas, mas também defendendo o direito a um mínimo decente de cuidados de saúde; ii) os casos deixam de figurar como apêndices e são examinados ao longo do próprio livro; iii) o princípio da autonomia é agora chamado "princípio do respeito pela autonomia," talvez com a intenção de aproximá-lo ao princípio do respeito pela pessoa do Relatório Belmont; iv) os apêndices com os diferentes códigos foram retirados. $O$ que essas mudanças significam? Maior atenção ainda às novidades trazidas por casos e pelo desenvolvimento técnico da biomedicina? A necessidade de ajustar princípios a casos e vice-versa? O reconhecimento da dependência de teorias éticas de certas filosofias políticas? Novamente, estaria operando aqui o ERA?

A quarta edição, publicada em 1994, revela que "esta edição inclui mais mudanças significativas que qualquer outra” (p. vii). Os principais pontos revisados foram os seguintes: i) o capítulo 1 traz novas seções sobre Método, Justificação e Verdade especificando e contrabalançando princípios com a introdução explícita do ER como "o método" adotado pelos autores (p. 23); ii) o lugar dos princípios na chamada "Moralidade Comum" é discutido; iii) no capítulo 2, novas seções sobre Individualismo Liberal, Comunitarianismo, a Ética do Cuidado, a Casuística e as Teorias-baseadasem-Princípios-e-na-Moralidade-Comum são introduzidas; iv) no capítulo 6, há uma seção nova sobre a Igualdade de Oportunidades (com uma significativa aproximação à teoria rawlsiana discutida acima) e os autores acrescentaram uma subseção sobre Distribuição de Cuidados de Saúde em termos de Gênero e Raça e outras seções foram acrescentadas sobre A Justificação na Assistência ao Morrer, o Valor e a Qualidade de Vida e a Racionalização através de Prioridades no Orçamento do Sistema de Saúde; v) nesta quarta edição, os autores não chamam mais, surpreendentemente, os quatro capítulos centrais de "princípios," a saber, a autonomia, não- 
maleficência, beneficência e justiça; vi) no capítulo 8, uma nova seção sobre virtudes nas funções profissionais explicitamente menciona a necessidade de 4 virtudes, a saber, a compaixão, o discernimento, a confiabilidade e a integridade; vii) finalmente, somente 10 casos são apresentados no final do livro. $\mathrm{O}$ que essas mudanças significaram em relação à adoção explícita do ERA? Mais teorização e menos engajamento com a discussão das particularidades dos casos? Reconhecimento que virtudes são elementos da vida moral e não apenas princípios e regras? Concessão aos críticos que princípios são vazios? Uma pergunta central aqui é a seguinte: a adoção do ERA não seria incompatível com a ideia de uma Moralidade Comum, isto é, com uma moral única composta por regras imutáveis para todos? Faz sentido aplicar o ERA se há esse comprometimento?

$\mathrm{Na}$ quinta edição do livro a essa altura já tornado clássico da bioética, publicada em 2001, o capítulo inicial sobre Justificação e Método foi transformado no capítulo 9 e as virtudes foram movidas do capítulo 8 para o 2, sendo inclusive acrescentada mais uma virtude à lista das quatro anteriores: a conscientiousness. A discussão sobre teorias éticas foi removida para o capítulo 8. Essas mudanças seriam efeitos da adoção do ERA? Em que sentido o ERA mostraria a minimização da importância da teorização ética e a incorporação gradativa de um enfoque ético que é, em certo sentido antiteórico, a saber, a ética de virtudes? Seria interessante o leitor, aqui, parar e observar as mudanças feitas até aqui e questionar-se sobre como está, supostamente, operando o ERA nessas reformulações.

Na sexta edição, publicada em 2009, as principais mudanças foram as seguintes: i) o capítulo 3, sobre status moral, é completamente novo; ii) há um engajamento maior com a Moralidade Comum nos capítulos 1 e 10; iii) no capítulo 7, dedicado à justiça, há uma discussão sobre globalização e sobre a nova ordem mundial a partir de certas teorias filosóficas; iv) no capítulo 2, a Ética do Cuidado foi revisada como uma forma da ética de virtudes e reconhecido o cuidado apenas como uma entre outras virtudes; v) os autores discutem detalhadamente o princípio da precaução; vi) o raciocínio prático não é considerado mais em termos exclusivos "de cima para baixo" ou "de baixo para cima”, mas o Equilíbrio Reflexivo é introduzido como um modelo integrador (voltarei a esse ponto a seguir); vii) mais surpreendentemente ainda, nos quatro capítulos centrais do livro, volta-se a chamar a autonomia, a não-maleficência, a beneficência e a justiça de "princípios morais" (título para a Part II, cf. p. 99). Que implicações têm a 
adoção do ERA a partir dessa edição do Principles? A resposta a essa questão, vai nos ocupar até o final da presente seção e na conclusão.

Feita essa reconstrução de algumas das constantes mudanças efetuadas no principialismo, é necessário agora discutir os termos da adoção "final" (quer dizer, antes que uma sétima edição do "livro sagrado" surpreenda ainda mais) do ER. Na seção intitulada "An Integrated Model Using Reflective Equilibrium” (p. 381-387), Beauchamp e Childress sustentam que tanto um procedimento "de cima para baixo" (princípios, regras) quanto "de baixo para cima” (casos, intuições) precisam de suplementação: princípios precisam ser especificados para casos; estes precisam justificação a partir de princípios. Nem dedutivistas puros nem indutivistas puros estão certos: "não há ordem fixa de inferência ou dependência do geral para o particular ou do particular para o geral.” (BEAUCHAMP \& CHILDRESS, 2009, p. 381). Por isso, a necessidade de um modelo integrador, do Equilíbrio Reflexivo. Como ironiza Arras, a próxima edição do "livro sagrado" da bioética deveria entitular-se: Considered Case Judgments, Principles, and Background Theories in Bioethics: How They Can All Be Brought in to Coherence With in the Ambit of Reflective Equilibrium (ARRAS, 2009, p.53, itálicos no original).

Depois de uma breve apresentação da noção de Equilíbrio Reflexivo em Rawls, os autores de Principles of Biomedical Ethics esclarecem que não são completamente coerentistas, ou seja, não sustentam que uma teoria da verdade como coerência seja suficiente. Segundo eles, um "Código de Ética Pirata” poderia ser perfeitamente coerente em seus princípios e regras, mas permitir várias ações consideradas imorais tais como seriam descritas por uma moral universal que, por exemplo, proíbe o roubo. Daí a necessidade de uma Moralidade Comum, proposta inicialmente por Gert, Culver e Clouser(1977) composta por regras universais incorporadas por Beauchamp e Childress (cf. 2009, p.3): não mate, não cause dor ou sofrimento; previna o dano etc. Tal Moralidade Comum apresenta normas iniciais, que funcionariam como fundações, mas que deveriam ser desenvolvidas através das constantes revisões, de cima para baixo, de cá para lá, de frente para trás, tal como exige o ERA. Por isso, os autores não são coerentistas e apenas seguem as linhas gerais do procedimento rawlsiano afastando-se da letra, embora não do espírito, do próprio Rawls (BEAUCHAMP \& CHILDRESS, 2009, p.385). Mais um efeito do próprio ERA? 
Há uma observação sobre o conteúdo do princípio da justiça que precisa ser feita no presente contexto. Em linhas gerais, Beauchamp e Childress seguem, nas últimas edições de seu livro, a teoria da justiça como fairness de Rawls com os desenvolvimentos feitos por Daniels na discussão sobre a aplicação dos princípios à questões bioéticas, principalmente de alocação micro e macro de recursos para a saúde. Nesse sentido, sem entrar nas particularidades da argumentação deles, cabe ressaltar que eles acabam por defender um sistema de saúde misto, público/privado, a partir da regra da igualdade de oportunidades. Não é possível, entretanto, aprofundar esse ponto aqui que merece um trabalho a parte.

Se houve progresso ou não na utilização do ER no principialismo, pode-se deixar ao leitor decidir a partir do estudo feito das diferentes edições do livro reformulando substancialmente o enfoque bioético predominante. Há, entretanto, um ponto a ser ressaltado. Apesar do uso do ERA, Beauchamp e Childress são incoerentes ao incorporar a ideia de uma Moralidade Comum, considerada a moralidade eterna, imutável etc., e defender ainda assim o uso do método do equilíbrio reflexivo. Se eles tornaram-se fundacionistas, então o ERA perde o sentido. Ao menos essa incoerência o ERA não eliminou.

Os próprios Beauchamp e Childress (2009, p. 387) são cientes dos limites do ERA e citam três problemas não resolvidos: i) a finalidade do método do ERA é ambígua; ii) não é claro como se deve proceder para atingir o equilíbrio e também não há critério para dizer quando ele foi atingido; iii) a justificação deve ser pública, mas a condição da publicidade não foi suficientemente desenvolvida. Em que medida esses problemas coincidem com as críticas de Arras será visto a seguir.

\section{Observações Finais}

Para começar, é necessário lembrar e sintetizar as críticas de Arras: o ERA é inconclusivo, ou seja, muito abrangente e muito indeterminado. Essas críticas são justas? Elas não são completamente justas, pois o próprio ERA foi concebido $a b$ initio como sendo inconclusivo e abrangente, ou seja, exigindo uma revisão contínua de todas as crenças, sejam princípios, sejam julgamentos ponderados cotidianos, sejam de outro tipo. O ERA inscreve-se numa epistemologia moral falibilista e, nesse sentido, ele é anti-dogmático por natureza exemplificando o melhor espírito filosófico e democrático. 
A crítica é, todavia, parcialmente justa, pois de fato o ERA é indeterminado de modo a produzir dano teórico. Concordo com Arras quando afirma que as funções omni-abarcadoras do ERA devem ser deflacionadas, pois tornam obscuro como se pode atingir o equilíbrio. Há algo de errado quando tantas teorias éticas são "assimiladas" como é feito no principialismo: os casuístas ouvem a parte que interessa do ERA (as particularidades dos julgamentos cotidianos nos diferentes casos); os teóricos de nível intermediário fazem um jogo dialético entre casos e princípios; finalmente, os filósofos puristas ouvem apenas a importância da teorização. Há, entretanto, divergências práticas e teóricas entre esses enfoques que o ERA não consegue eliminar ou superar. Não seria irrealista também esperar convergência entre, digamos, consequencialistas radicais e deontologistas ortodoxos na ética normativa ou entre céticos morais e realistas na metaética? Que convergência possível se poderia esperar entre os modelos autonomista de Engelhardt (1996) e da beneficência-na-confiança de Pellegrino (1988) ou entre eles que são não-intuicionistas e os principialistas que são intuicionistas no sentido rawlsiano? Bioeticistas como Jonsen consideram que entre um princípio como o do respeito pela pessoa, que aparece no Relatório Belmont, e o princípio do respeito pela autonomia do principialismo há um "abismo moral”. O que poderia fazer o ERA para superar essa divergência? Aparentemente, pace Daniels e Beauchamp e Childress, não é possível uma convergência completa entre todas as teorias.

Quanto a possíveis funções positivas, a coerência total e completa entre todas as nossas crenças, talvez seja apenas um ideal, espera-se não utópico, cuja praticalidade já Rawls desconfiava em 1971: "it is doubtful whether one can ever reach this state" ("é duvidoso se alguém pode, em algum momento, alcançar este estado”. Diante do estado da arte da bioética atual uma pequena aproximação a este estado seria desejável, embora pareça distante de ser alcançado. Arras pensa que o ERA é, de fato, inalcançável, sendo apenas um ideal regulador (ARRAS, 2009, p.67).

Há, finalmente, um papel importante para o ERA, mas é uma função meramente negativa: a de filtrar as nossas crenças eliminando incoerências, inconsistências etc.. Não há porque não subscrever esse ideal regulador, mesmo que se tenha também que começar, por exemplo, afirmando que certos julgamentos ponderados não dão tanta prioridade às liberdades rawlsianas e por isso é preciso rediscutir o seu primeiro princípio e suas implicações para a bioética. Há outros elementos da filosofia política de 
Rawls, Daniels e, em alguma medida de Beauchamp e Childress, que também não se encaixam com certos julgamentos cotidianos, por exemplo, se o consenso é o critério da verdade ou a verdade produz consensos, se há prioridade do correto sobre o bom, se o político tem primazia em relação ao ético, se não é necessário mais igualdade e menos liberdades etc., mas não é este o momento de tratar dessas divergências que talvez o ERA não ajude a superar.

A conclusão, que dentro do melhor espírito do ERA deve ser provisória, é que o método de justificação do equilíbrio reflexivo é um procedimento útil para a investigação bioética, mas ele é insatisfatório e não pode funcionar isoladamente. Crenças, além de formarem um todo coerente, precisam de correspondência com a realidade e, nesse sentido, o ERA não estabelece nenhum critério seguro para testá-las. Nesse sentido, a crítica que ele é inconclusivo porque é muito abrangente pode ser relevada, mas não a crítica que ele é inconclusivo porque é indeterminado. Por conseguinte, podese continuar usando o equilíbrio reflexivo na bioética, mas é necessário deflacionar as suas pretensões e ter presente os seus limites.

\section{REFERÊNCIAS BIBLIOGRÁFICAS}

ARRAS, J. "The Way We Reason Now: Reflective Equilibrium in Bioethics." In: STEINBOCK, B. The Oxford Handbook of Bioethics. Oxford: Oxford University Press, 2007. P. 46-71.

BEAUCHAMP, T. \& CHILDRESS, J. Principles of biomedical ethics. Oxford: Oxford University Press, 2009. (Edições anteriores consultadas: 2001, 1994, 1989, 1983, 1979).

DALL’AGNOL, D. Bioética: princípios e aplicações. Rio de Janeiro: DP\&A, 2004.

DANIELS, N. Reading Rawls: a critical study of Rawls' A Theory of Justice. Stanford University Press, 1989.

. Just Health Care. Cambridge: Cambridge University Press, 1985.

- Justice and Justification. Reflective equilibrium in theory and practice. Cambridge: Cambridge University Press, 1996. 
DWORKIN, R. The Original Position. [1975]. In: DANIELS, N. Reading Rawls. Critical studies in Rawls' A theory of justice. Stanford: University Press, 1989. p. 16-53

ENGELHARDT, T. The Foundations of Bioethics. Oxford: Oxford University Press, 1996.

GERT, B. \& CULVER, C.M. \& CLOUSER, K.D. Bioethics: a return to fundamentals. New York/Oxford: Oxford University Press, 1997.

GOODMAN, N. Fact, Fiction and Forecast. Cambridge, Mass.: Harvard Univeristy Press, 1983.

HOBUSS, J. (org.) Ética das virtudes. Florianópolis: Edufsc, 2011. (Série Ethica)

PELLEGRINO, E. \& THOMASMA, D. For the patient's good. New York/Oxford University Press, 1988.

RAWLS, J. A Theory of Justice. Cambridge (Mass.): Harvard University Press, 1979.

RAWLS, J. Political Liberalism. New York: Columbia University Press, 1993.

RAWLS, J. Collected Papers. Cambridge (Mass.)/London: Harvard University Press, 1999.

RAWLS, J. Justice as fairness: a Restatement. Cambridge (Mass.)/London: Harvard University Press, 2003.

SILVEIRA, D. C. Ensaios sobre Ética. Pelotas: Editora e Gráfica Universitária, 2008.

TUGENDHAT, E. Probleme der Ethik. Stuttgart, 1984.

WITTGENSTEIN, L. On Certainty. New York: Blackwell, 1969. 